\title{
Sexual and Reproductive Health Services and Promotion in Tertiary Institutions: A Systematic Content Review
}

\author{
Jack DeLacy \\ Faculty of Medicine and Health \& \\ The Sax Institute \\ The University of Sydney \\ Rowena Saheb \\ Erin Rutherford \\ Student Experience Office \\ Western Sydney University \\ Raul G Garcia \\ School of Computing and Engineering \\ Western Sydney University \\ Tinashe Dune \\ School of Science and Health \& \\ Translational Health Research Institute \\ Western Sydney University
}

\begin{abstract}
Sexual and reproductive health (SRH) is increasingly being recognised as a key concern for young people within tertiary settings. This is reflected within the Okanagan Charter: An International Charter for Health Promoting Universities and Colleges. In response, tertiary institutions around the world have developed and are developing SRH promotion and services to meet the needs of their students. However, the scope and duration of such programs vary across institutions. To identify best practice within this area, a systematic scoping content review of scholarly literature published in English was conducted. The review sought out research conducted in Australia, USA, Canada, UK and New Zealand. Findings from the review were used in the development of a SRH program at an Australian university. Results indicate that the capacity for programs to have significant positive impact on university students is highly dependent on a range of SRH priorities. These priorities include utilising pilot programs in the development and evaluation of SRH initiatives, including peers in the delivery of SRH services, identifying key demographics and high-risk sub-populations within the institution and surrounding geographical area, providing targeted SRH education, and ensuring accessibility to STI screening and contraception on campus. Key lessons include the importance of an integrated approach in delivering SRH programs, where the departments leading such initiates have buy-in and support from a range of stakeholders across the institution. A best practice model for the development and delivery of SRH programs at tertiary institutions, in line with the Okanagan Charter, is recommended.
\end{abstract}

\section{Keywords}

Sexual health, Reproductive health, Tertiary Institutions, Sexually Transmitted Infections, Sexually Transmitted Diseases, Pregnancy, Family Planning

\section{Introduction}

Adolescence and young adulthood are important psychosociosexual developmental times where young people are exploring or affirming their sexual identity, orientation, agency, desires and expectations (Eisenberg et al, 2013; Holt \& Powell, 2016; Skinner \& Hickey, 2003). It is also a time that may be subject to confusion, coercion, risk taking and experimentation, and is therefore clear that navigating this psychosociosexual terrain can present young people with a range of challenges (Eisenberg et al, 2013; Holt \& Powell, 2016; Skinner \& Hickey, 2003) - a reality that tertiary education providers cannot ignore. Given that around $45 \%$ of young people in OECD 
(Organisation for Economic Co-Operation and Development) countries attend tertiary institutions (OECD Data, 2017), education providers have a duty of care over their students health and wellbeing experiences during their studies (Holt \& Powell, 2016). This expectation is reinforced by documents like the 'Okanagan Charter: An International Charter for Health Promoting Universities and Colleges' (ACHA, 2015).

\section{The Okanagan Charter and student sexual and reproductive health}

The Okanagan Charter was an outcome of the 2015 International Conference on Health Promoting Universities and Colleges (VII International Congress) held in British Columbia, Canada. As noted within the document (ACHA, 2015), the purpose of the Charter is threefold:

i. Guide and inspire action by providing a framework that reflects the latest concepts, processes and principles relevant to the Health Promoting Universities and Colleges movement, building upon advances since the 2005 Edmonton Charter.

ii. Generate dialogue and research that expands local, regional, national and international networks and accelerates action on, off and between campuses.

iii. Mobilize international, cross-sector action for the integration of health in all policies and practices, thus advancing the continued development of health promoting universities and colleges. (p. 3)

In line with these aims, the Charter (ACHA, 2015) has two Calls to Action for higher education institutions:

1. Embed health into all aspects of campus culture, across the administration, operations and academic mandates.

2. Lead health promotion action and collaboration locally and globally. (p. 3)

Although the Okanagan Charter does not explicitly mention Sexual and Reproductive Health (SRH), acknowledging and addressing it as part of tertiary student life aligns with the Charter's focus on holistic health promotion. Given that SRH is central to the human experience for many people, it is important that tertiary institutions embed SRH into all appropriate aspects of tertiary student life, by engaging in health promotion and service delivery, which acknowledges the realities of student life (Holt \& Powell, 2016). This proposition is supported by definitions of SRH, which encompass a more holistic approach to health and wellbeing. For instance, according to the World Health Organization (WHO) (2006), sexual health is:

A state of physical, emotional, mental and social wellbeing in relation to sexuality; it is not merely the absence of disease, dysfunction or infirmity. Sexual health requires a positive and respectful approach to sexuality and sexual relationships, as well as the possibility of having pleasurable and safe sexual experiences, free of coercion, discrimination and violence. For sexual health to be attained and maintained, the sexual rights of all persons must be respected, protected and fulfilled. (p. 5)

Similarly, WHO (2005) defines reproductive health in an equally expansive way, where the term implies that "people are able to have a responsible, satisfying and safe sex life and that they have the capability to reproduce and the freedom to decide if, when and how often to do so" (WHO, 2005, p.5). Implicit in this definition are reproductive rights, which as defined by WHO (2005) state:

Reproductive rights rest on the recognition of the basic right of all couples and individuals to decide freely and responsibly the number, spacing and time of their children and to have the information and means to do so, and the right to attain the highest standard of sexual and reproductive health. It also includes their right to make decisions concerning reproduction free of discrimination, coercion and violence, as expressed in human rights documents. (p.5) 
As implied in the above definitions and substantiated by a significant amount of research, failure to support the SRH needs of young people can result in serious social, cultural, economic, legal and health issues (Wilson, Steenbeek, Asbridge, Cragg, \& Langille, 2016). These issues can include unplanned pregnancy, sexual coercion and violence, sexually transmitted infections (STIs) and infertility (Eastman-Mueller, Gomez-Scott, Jung, Oswalt \& Hagglund, 2016; Eisenberg et al, 2013; Holt \& Powell, 2016; Wilson et al, 2016). Often, these outcomes are also linked to low levels of SRH literacy and agency, and limited provision and access to SRH information and services (Eisenberg et al, 2013; Wilson et al, 2016). Poor SRH is consequently linked to economic burden for young people, families and society (Skinner \& Hickey, 2003; Temple-Smith \& Gifford, 2005; Women's Health West, 2011). Considering these far-reaching effects and the cost of neglecting $\mathrm{SRH}$, research encourages governments and institutions to invest in improving young people's SRH outcomes (Jacobsen et al, 2002; Singh, Darroch, Ashford, \& Vlassoff, 2009; Vlassoff, Singh, Darroch, Carbone, \& Bernstein, 2004). Within OECD countries, there is growing consensus on the importance of SRH promotion and services within tertiary environments (ACHA, 2015; Holt \& Powell, 2016). However, there remains little guidance on how to develop and evaluate targeted SRH programs within these environments that aim to ensure their efficacy.

This review seeks to collate best practice principles for SRH programming in tertiary institutions. The next sections review literature related to tertiary students' SRH, and the impact that SRH promotion and services may have on the health and wellbeing of students within tertiary settings. Subsequent sections delineate the methods and results of the review, with a final discussion on opportunities and limitations found in implementing SRH promotion and services within tertiary environments.

\section{Sexual and Reproductive Health Concerns amongst Young People in Australia}

In Australia, contracting an STI and experiencing unplanned pregnancy are the main areas of concern for young people. Chlamydia is one of the most prevalent STIs amongst young people in Australia. According to the Kirby Institute (as cited in AIHW, 2017) chlamydia notification rates increased significantly between 1999 and 2011 - from 74 to 363 infections per 100,000 people. Between 2011 and 2016 rates slowly increased to 385 infections per 100,000 people. In 2012, 80\% of cases were seen in people aged 15 to 24 years old (ABS, 2012). According to MacPhail and colleagues (2017) only $60 \%$ of secondary students know that chlamydia can affect both men and women, and only $56 \%$ know that chlamydia can produce sterility in women. This suggests poor SRH literacy amongst young people and highlights the need for SRH health education for young people and students. Without effective SRH programming, there is limited opportunity to counteract misinformation therefore, this hinders efforts to reduce the spread of chlamydia amongst young people (MacPhail et al, 2017).

Recent data shows that Australia has the sixth highest teenage pregnancy rate among OECD countries (Skinner \& Hickey, 2003). Whilst teen birth rates are lower than those in the UK and USA, in 2011 the Australian birth rate among teenage women (13-19 years old) was 15.6 per 1000 live births (Family Planning Victoria, 2015). Compared to Germany (10/1000), France (8/1000) and the Netherlands (4/1000) Australian young women are between 1.5 to 3.5 times more likely to become teen mothers. In Australia almost half of all pregnancies are unplanned (Skinner \& Hickey, 2003 ), and over $55 \%$ of these unplanned pregnancies result in parenting, $29 \%$ in abortion and $2 \%$ in adoption (Children By Choice, 2017).

New advances in technology are transforming the way young people experience and engage with their SRH (Currie et al, 2010). This includes the ways in which they are seeking out SRH information and how they are engaging with potential sexual partners (Currie et al, 2010). While this digitisation of sexuality is not inherently problematic, strategies to support tertiary students engaging in a variety of sexual mediums is important to consider when seeking best practice 
guidelines for SRH service development and implementation.

\section{Home and Away: Exploring SRH promotion and services in Australia and abroad}

This review initially aimed to explore information from Australian studies about SRH services in tertiary education environments. However, following a preliminary search, less than five studies from Australia were identified. Due to the scarcity of local evaluations on the impact and effectiveness of SRH services within tertiary institutions in Australia, this review also sought out research conducted in the USA, Canada, UK and New Zealand. By comparing against countries like Australia, we hoped to better understand and develop SRH promotion and services that were responsive to tertiary students.

The four countries (USA, Canada, UK and New Zealand) were chosen due to shared demographic characteristics with Australia. Notably all five countries have a dominant Anglo-Saxon ethnocultural framework (Cronin, 2012). This framework is closely linked to the UK, with the British being colonisers in Australia, Canada, New Zealand and USA (Cronin, 2012). Additionally, all five countries are highly multicultural, neo-liberal, capitalist and democratic (Cronin, 2012). Using Geert Hofstede's (n.d.) six cultural dimensions, the similarities (and differences) between these five countries are quantified and summarised (see Figure 1).

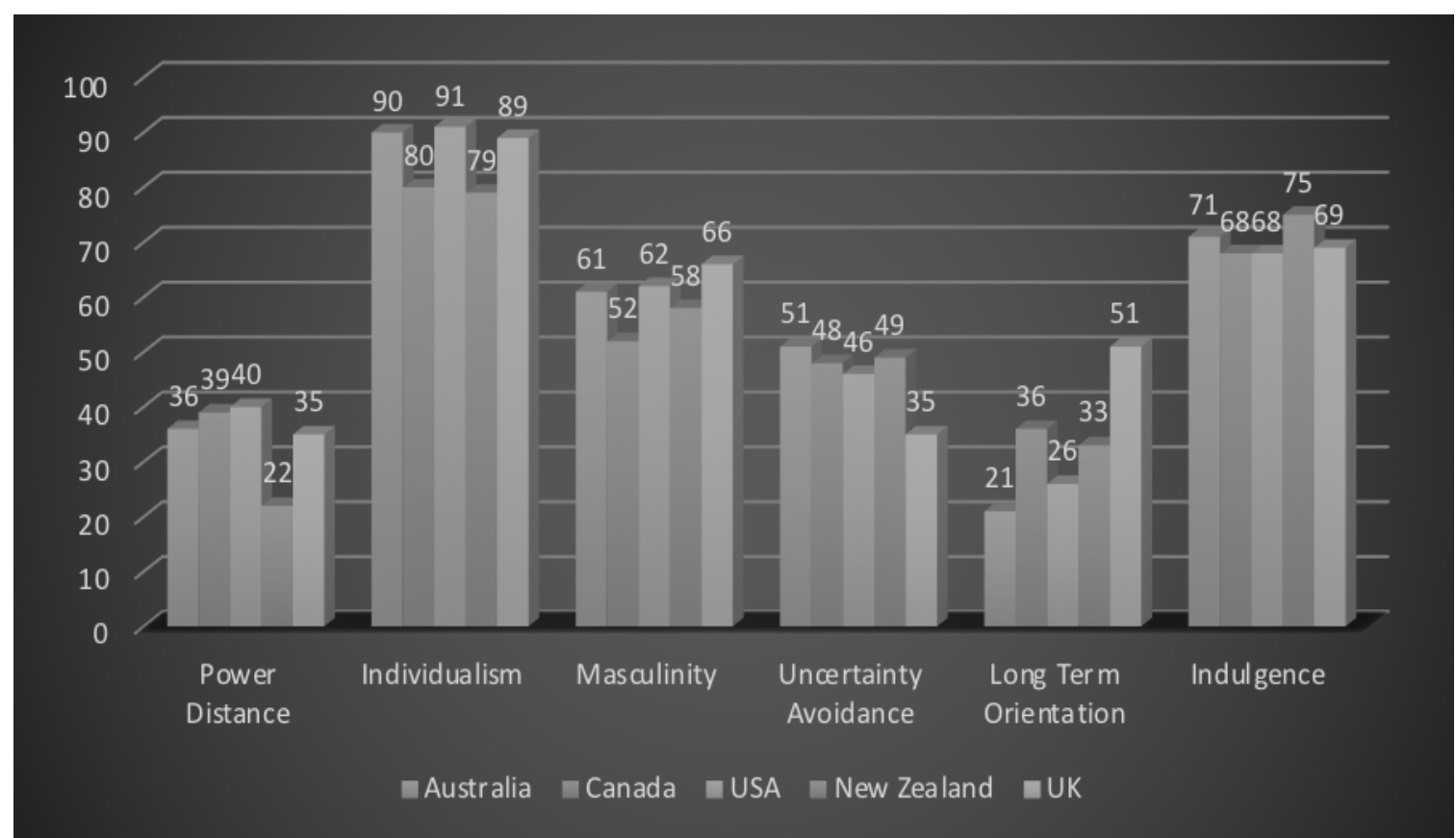

Figure 1. Geert Hofstede's cultural dimensions comparison for Australia, Canada, USA, New Zealand and the UK (Hofstede, n.d.).

\section{Methods}

Given the broad nature of the research objective, a scoping content review was conducted to explore available research, to evaluate the need for further investigation, to describe key themes and to identify gaps in the literature. The framework proposed by Arksey and O'Malley (2005) for conducting a scoping content review was adapted for this study and is detailed below.

\section{Search Strategy}

Between December 2016 and January 2017, nine databases (i.e., Proquest Central, EBSCOhost, CINAHL, Pubmed, MEDLINE, PsycINFO, SocINDEX, Scopus and Infomit) were searched for peer-review and grey literature. The keywords, inclusion and exclusion criteria were initially established by author RG and then subjected to scrutiny and consensus with the other authors. Table 1 summarises the search parameters. 
Table 1. Summary of the inclusion/exclusion criteria and keywords

\begin{tabular}{|c|c|c|c|}
\hline Parameters & Inclusion & Exclusion & Key words/steps \\
\hline Location & $\begin{array}{l}\text { Australia, New Zealand, } \\
\text { United Kingdom, USA } \\
\text { and Canada }\end{array}$ & Other countries & $\begin{array}{l}\text { Australia* OR Oceania OR "South Pacific" OR } \\
\text { "United States of America" OR USA OR "United } \\
\text { States" OR America OR "North America" OR } \\
\text { Canada OR Canadian* OR "United Kingdom" OR } \\
\text { Britain OR England OR "English People" OR } \\
\text { Scotland OR Scottish OR Celtic OR Highlands OR } \\
\text { Wales OR Welsh OR UK OR "Great Britain" OR } \\
\text { "Western Europe" OR "New Zealand" OR "U.S." }\end{array}$ \\
\hline Language & Written in English & Other languages & Select for English only. \\
\hline Time & Any & None & N/A \\
\hline Setting & $\begin{array}{l}\text { Tertiary education } \\
\text { institutions }\end{array}$ & $\begin{array}{l}\text { Non-tertiary } \\
\text { education } \\
\text { institutions }\end{array}$ & $\begin{array}{l}\text { Universit* OR College OR “technical college" OR } \\
\text { TAFE OR polytechnic OR "tertiary institution" OR } \\
\text { "tertiary studies" }\end{array}$ \\
\hline Population & $\begin{array}{l}\text { Studies focused on } \\
\text { tertiary populations }\end{array}$ & $\begin{array}{l}\text { Literature which } \\
\text { do focus only in } \\
\text { Sexual Health }\end{array}$ & $\begin{array}{l}\text { Student* OR Youth OR "Young People" OR } \\
\text { adolescent OR “young adult” OR staff OR Teachers } \\
\text { OR Educators }\end{array}$ \\
\hline Phenomena/Target & $\begin{array}{l}\text { Studies concerned with } \\
\text { the impact of the Sexual } \\
\text { Health Services in } \\
\text { Universities }\end{array}$ & $\begin{array}{l}\text { Not concerned } \\
\text { with the impact of } \\
\text { the Sexual Health } \\
\text { Services in } \\
\text { Universities }\end{array}$ & $\begin{array}{l}\text { "Sexual Health" OR "family planning" OR "sexual } \\
\text { and reproductive health" OR "Reproductive health" } \\
\text { OR Contracept* OR "Sexually transmitted } \\
\text { infection" OR "Sexually transmitted disease" OR } \\
\text { STI OR "Sexual risk behavior" OR "Sexual risk } \\
\text { behaviors" OR "Sexual risk behaviour" OR "Sexual } \\
\text { risk behaviours" OR "Sexual risk attitude" OR } \\
\text { "Sexual risk intentions" OR "Sexual risk intention" }\end{array}$ \\
\hline Health Intervention & $\begin{array}{l}\text { Studies reporting on } \\
\text { results of a health } \\
\text { intervention }\end{array}$ & $\begin{array}{l}\text { Not examining } \\
\text { the delivery of a } \\
\text { health } \\
\text { intervention }\end{array}$ & $\begin{array}{l}\text { Service* OR program* OR education OR training } \\
\text { OR "health promotion" OR resources OR } \\
\text { intervention OR prevention OR "preventative } \\
\text { health" OR "primary prevention" }\end{array}$ \\
\hline $\begin{array}{l}\text { Study/ literature } \\
\text { type }\end{array}$ & $\begin{array}{l}\text { Published primary } \\
\text { research including } \\
\text { qualitative, quantitative } \\
\text { and mixed method } \\
\text { designs }\end{array}$ & $\begin{array}{l}\text { Unpublished } \\
\text { literature }\end{array}$ & $\mathrm{N} / \mathrm{A}$ \\
\hline
\end{tabular}

\section{Quality assessment and selection of literature}

After searching the documents, a selection of articles and research findings, was identified. Due to differences within the studies, this review includes different types of sexual and reproductive health services and promotions. Considering the heterogeneous nature of the studies included, especially the variety of methodologies used, it was not possible to compare them to each other. Consequently, an assessment of the quality of individual studies was not performed. Further, given that this review aimed to provide an overview of extant research with respect to the development, evaluation and impact of SRH programs in tertiary education settings, analysing the methodological quality of individual studies was not appropriate (Ahmed et al, 2016).

\section{Collating, analysing and reporting results}

Following the inclusion procedure and quality assessment process, the included literature was placed into an Excel spread sheet for analysis. The literature was analysed based on the following parameters: 'what services are discussed?', 'what is the targeted problem?', 'what development and evaluation methods are discussed?', 'what is the impact of these services (students and staff) and what recommendations are made?', 'are tertiary institutions mentioned as important for implementing SRH services and intervention?', and are either of the two key areas ('creating supportive campus environments' and 'developing trans-disciplinary local and global collaborations') of the Okanagan Charter mentioned? 


\section{Themes}

A second analysis was performed after identifying important recurrent aspects of SRH, mentioned within the selected literature. The recurring themes that were analysed included barriers to implementing SRH services, the use of pilot studies, alcohol consumption, contraception, type of contraception mentioned, STI screening, peer involvement, high-risk sub-populations, gathering of demographic information and SRH education. Key criteria for identifying recurring themes and key considerations for SRH within tertiary environments were identified within the literature by identifying and selecting themes discussed by at least a third of the selected literature. Given the broad nature of this review, there were many areas of SRH addressed within the literature, and the threshold for significance (30\%) was established by the lead author and subsequently agreed upon by all other authors. The themes identified and critically evaluated were: barriers to SRH promotion on tertiary campuses, alcohol consumption and its impact on sexually risky behaviour, the use of pilot programs when implementing SRH research or on-campus services, the use of contraception, STI screening, peer involvement and SRH education programs.

\section{Results}

The literature search was conducted on the nine specified databases and the exclusion process is detailed in Figure 2. The search yielded 813 results with 199 articles deleted because of duplicates and a further 572 excluded because of irrelevance to the title. A further 25 articles were excluded because of irrelevance to the abstract and one more article was excluded, as the sample were highschool students. From 813 identified documents, 16 were included in this review (see Figure 2).

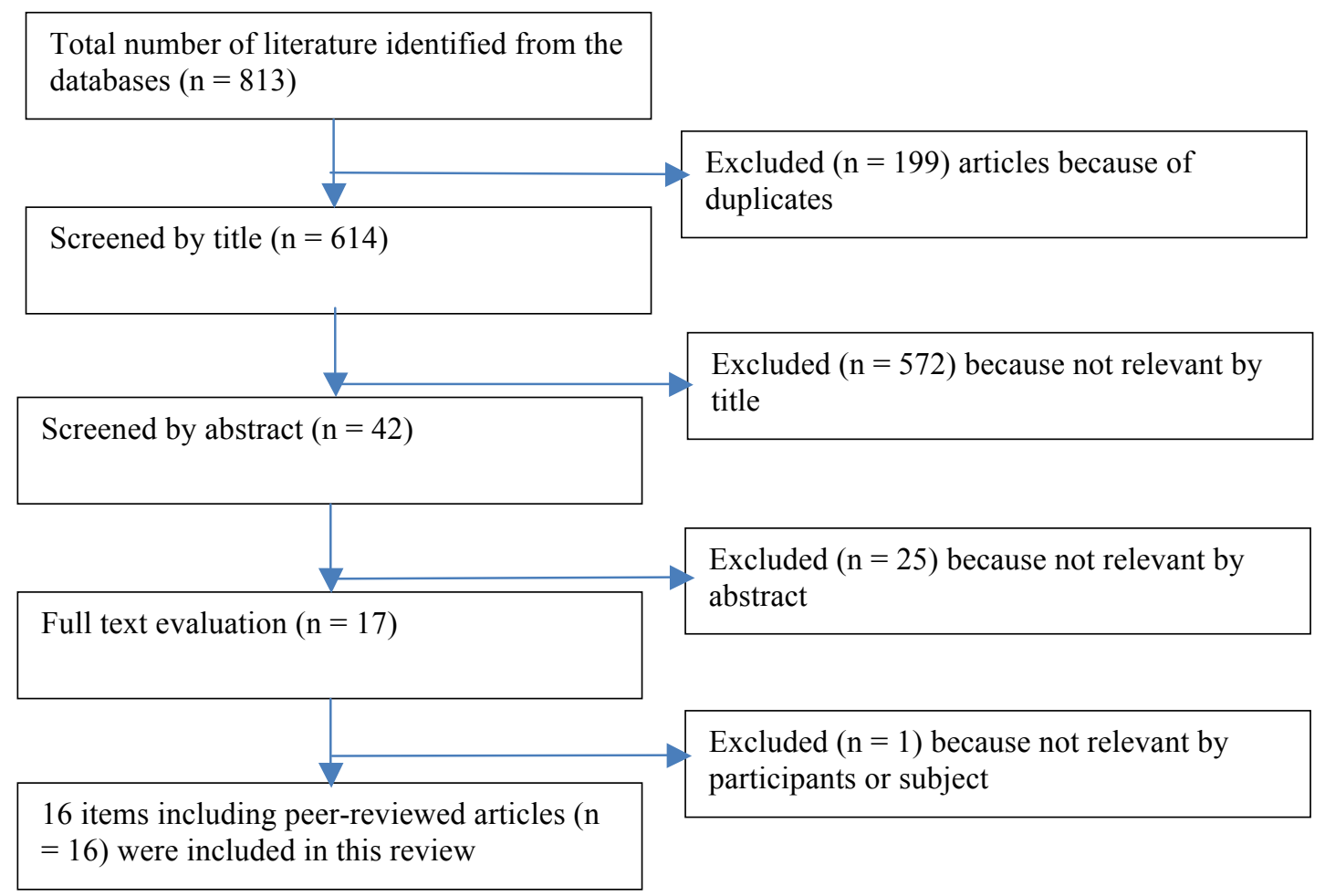

Figure 2. Article selection process and outcome

\section{Sample}

The characteristics of each study are summarised in Table 2. This review summarises the perspectives of 70,478 university students and staff. Most studies focused only on student cohorts (9) and fewer focused on staff and students (4) or only staff (2). While the majority of studies did not focus on a particular ethnocultural group, a few focused specifically on university students from defined cohorts: Canadian Aboriginal (1), French-Canadian (1) and Asian students (1). The vast 
majority of research was conducted in the United States (8) with the remainder in the United Kingdom (3) Canada (2), Australia (2), Hong Kong (1) and New Zealand (1).

\section{Research Foci and Theoretical Approach of the Studies}

The studies primarily focused on evaluating different methods of SRH interventions/promotion including: STI testing and/or HPV vaccination (4), condom provision (3), SRH education (4), emergency contraceptive pill availability (2), SRH services (2) and student opinions/knowledge about SRH (1). All studies implicitly or explicitly aimed to make recommendations about SRH promotion development and evaluation towards improving student SRH outcomes. Only four papers explicitly indicated the use of a theoretical framework to guide the research. Those that did used either a Sexual Health Promotion (3) or a Health Promotion (1) model/framework.

\section{Research Design and Methodology}

Quantitative methodologies using surveys (10) were the most common data collection strategy. Five used qualitative approaches, with interviews and open-ended responses on questionnaires being most common. One used a mixed methods approach. Given the emphasis on quantitative methods, a variety of statistical analyses were applied including descriptive statistics, chi-squared test, frequency distribution, t-tests, McNemar test (binominal distribution), Wilson Score Method, Logistic Regression, Multilevel Regression, percentage and Simple Proportions. Qualitative studies undertook thematic or content analyses.

\section{Findings}

Less than half of the selected literature $(7=43.7 \%)$ mentioned tertiary institutions as important environments for implementing SRH services within the community. The vast majority of the selected literature $(14=87.5 \%)$ mentioned supportive campus environments as essential to the success and overall efficacy of SRH services on tertiary campuses. $50 \%$ of the selected literature (8) mentioned trans-disciplinary collaboration as important for the success of SRH services on tertiary campuses. Only one paper (6.25\%) amongst the selected literature directly mentioned the Okanagan Charter.

Alcohol was reported, by $37.5 \%$ of the selected literature (6), as a factor contributing to sexually risky behaviour and related decision-making by college and university students. High-risk sub populations were discussed in 6 papers $(37.5 \%)$ as important target groups for SRH services and demographic information gathering was implemented by 9 SRH services $(56.25 \%)$ examined in the selected literature. Five papers (31.25\%) reported using a pilot study prior to implementing SRH health services on campus and 13 papers $(81.25 \%)$ emphasised the importance of implementing education as part of SRH programs. Peer involvement in the implementation and promotion of SRH services on tertiary campuses was reported by 7 papers $(43.75 \%)$ to be essential for greater uptake of services by students.

Sexually transmitted infection (STI) screening was offered by $10(62.5 \%)$ of the SRH programs discussed within the literature. The use of birth control $(13=81.25 \%)$ and unplanned pregnancy $(9$ $=56.25 \%$ ) was frequently reported within the literature as a crucial SRH issue, most significantly effecting female students. Contraception was reported by the vast majority of papers $(13=81.25 \%)$, with condoms the highest reported method of contraception $(10=62.25 \%)$ followed by oral contraception $(8=50 \%)$. 


\section{Table 2. Characteristics of included studies}

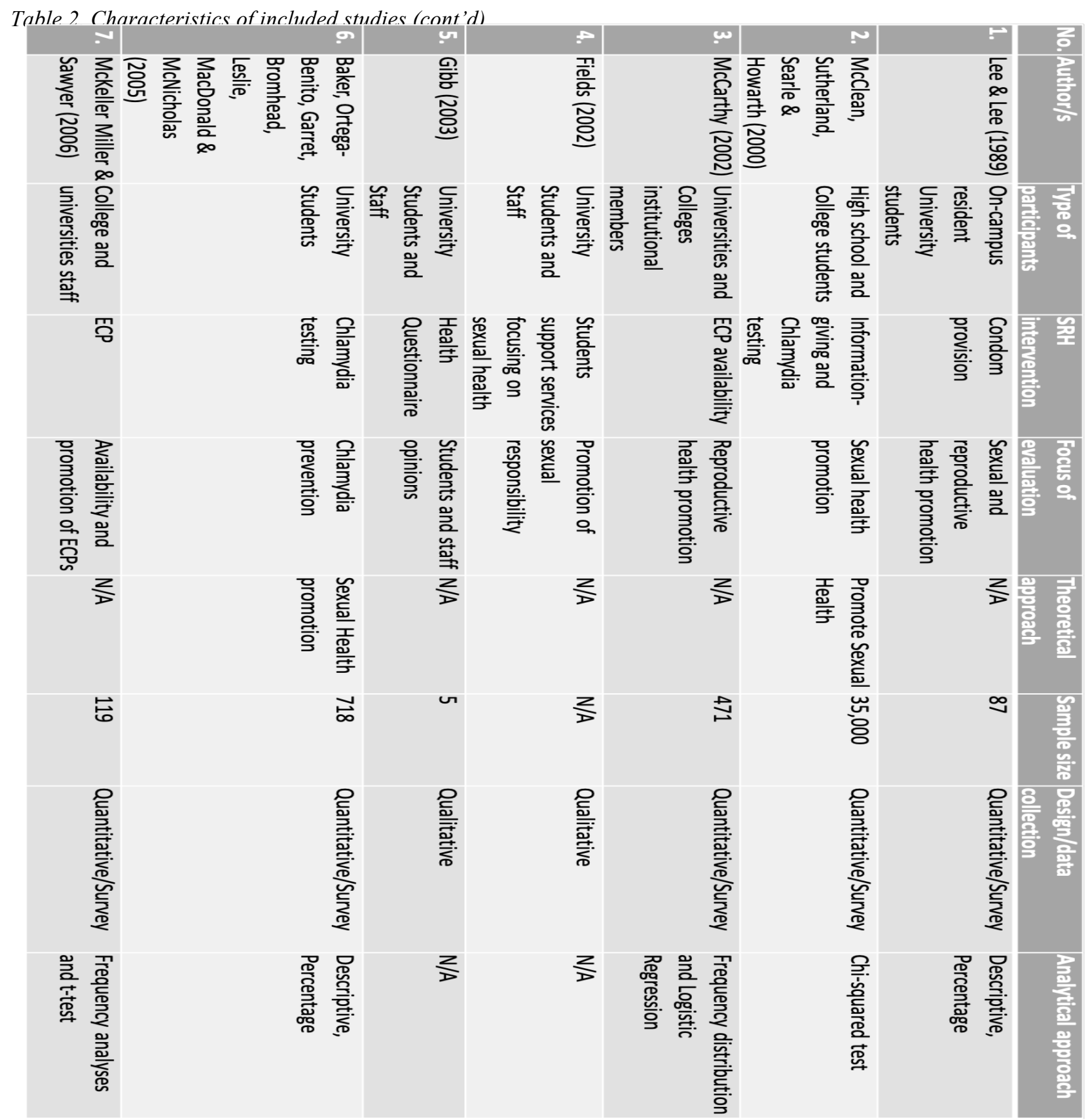




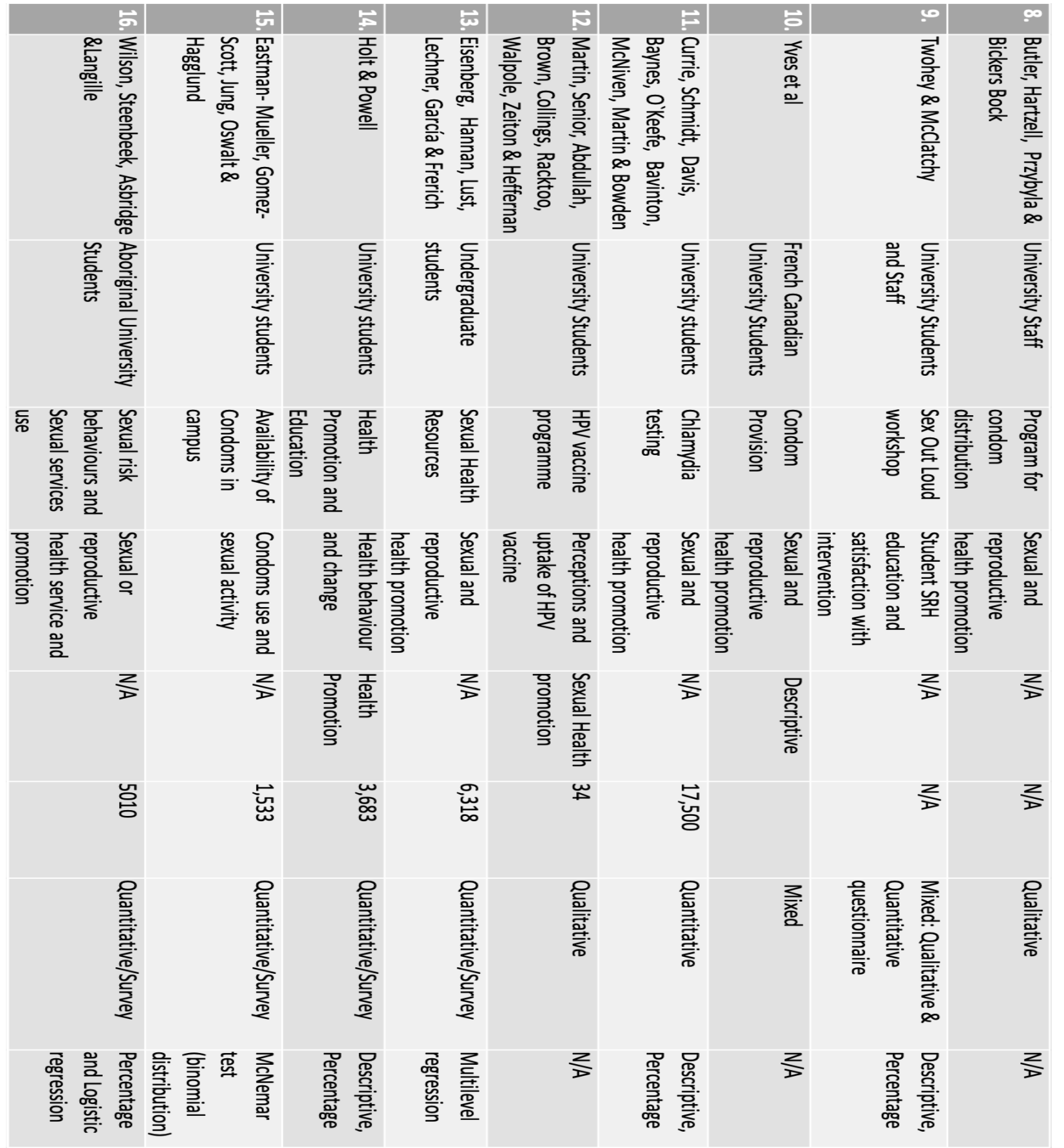




\section{Discussion}

Sexual and reproductive health is a major health concern among young adults, and therefore college and university students can be considered a priority population when addressing this area of public health. Further, implementation of SRH services on tertiary campuses can play a major role in addressing high-risk sexual behaviour and key risk factors for sexually transmitted infections. The importance of SRH services on tertiary campuses is emphasised by Eisenberg et al (2013, p135) who states, "the higher the level of sexual health resources at a college campus, the lower the likelihood of intercourse without birth control, intercourse without a condom and involvement in unplanned pregnancy". It is clear that such services are essential in providing holistic health care for young adults and university students. In accordance with the Okanagan Charter, many tertiary institutions around the world have been incorporating more holistic approaches to health promotion on campus. This review aims to identify the strengths and limitations of SRH services implemented in universities across Australia, USA, Canada, the UK and New Zealand. Furthermore, this review evaluates the effectiveness of the Okanagan Charter to guide the development and implementation of SRH services on tertiary campuses, highlights key themes within the literature and identifies gaps within the literature.

\section{Okanagan Charter and sexual and reproductive health}

The Okanagan Charter is a framework for Universities and Colleges to promote holistic health through trans-disciplinary and cross-sector collaboration. The Okanagan Charter aims to guide tertiary institutions in the prevention of key health concerns and provides an outline to create salutogenic environments for students, staff and the wider community (ACHA, 2015). However, it is important to note that the Okanagan Charter does not directly discuss or provide guidance for SRH. Similarly, this review only identified one paper that directly mentions the Okanagan Charter and less than half of the papers reviewed (43.75\%) specifically mentioned tertiary campuses as important environments for promoting SRH. It is therefore clear that there is a need to bridge the gap between health frameworks, such as the Okanagan Charter, and available literature on student focussed SRH initiatives. This review helps to bridge the gap by identifying key considerations for tertiary institutions implementing SRH services on campus. These key considerations include the need for pilot programs when implementing SRH services, overcoming barriers, alcohol consumption and its influence on sexually risky behaviour, STI screening, identification of highrisk sub-populations, the use and availability of contraception, peer involvement in the delivery of services and SRH education on campus.

\section{Overcoming barriers and the Okanagan Charter}

Two key areas of the Okanagan charter- 'creating supportive campus environments' and 'developing trans-disciplinary local and global collaborations', were analysed in this review and findings showed that 'creating supportive campus environments' was mentioned as important for promoting SRH by the vast majority of the literature $(87.5 \%)$. Further, 'developing transdisciplinary local and global collaborations' was mentioned by half of the literature $(50 \%)$. It is clear that these aspects of health promotion on campus are essential to creating healthy environments and should be embraced by administrators and health promoters alike. The barriers to implementing SRH services within tertiary environments, as identified in this review were overwhelmingly homogeneous, with 10 of the 16 papers reviewed identifying religious or ideological barriers as primary obstacles for promoting SRH on campus. Therefore, it needs to be emphasised that regardless of a tertiary institutions religious or ideological affiliations, creating supportive campus environments and facilitating trans-disciplinary collaboration is essential to achieving positive SRH outcomes within the local and wider community. To create safe environments and encourage collaboration, key aspects of SRH promotion need to be accepted by 
all stakeholders. These key aspects include the promotion, availability and accessibility of contraception, STI screening and SRH education. It is crucial to emphasise that any barrier to the promotion and provision of these services is likely to create a barrier to improving the overall health and wellbeing of students, staff and the wider community.

\section{Pilot programs}

Pilot programs can play an important role in the initial stages of a large project or study. For example, pilot studies can help to identify the feasibility and consequential alterations needed in the planning and design process (Leon Davis, \& Kraemer, 2011). It is however important to note that there are no widely accepted guidelines for implementing pilot studies, despite their importance for understanding the effectiveness of applied interventions (Kistin \& Silverstein, 2015). Kistin and Silverstein (2015) emphasise the importance of cautiously analysing and interpreting the results from pilot studies, as unjustified conclusions are often drawn as a result of the lack of clear guidelines. Eisenberg et al (2013) detail utilising pilot studies as a means to test updates and changes to SRH programs to ensure that annual revisions are tested for reliability and efficacy prior to their ongoing inclusion in the program. Furthermore, two of the papers scoped in this review (Butler, Hartzell, Przybyla, \& Bickers Bock, 2006; Eastman-Mueller, Gomez-Scott, Jung, Oswalt, \& Hagglund, 2016) discuss the benefits of utilising pilot programs to ease concerns from administration, program coordinators and other stakeholders. It is clear that pilot studies have a vital role in the development of on-campus SRH services and should be utilised in the initial development and ongoing revisions of such services. This is highlighted throughout the literature and within this review, with $31.25 \%$ of the scoped literature emphasising the benefits of pilot programs in the implementation and revision of SRH services on campus.

\section{Alcohol consumption}

Students entering tertiary environments are likely to have greater access to alcohol, higher numbers of sexual partners and increased independence (Butler et al, 2006). Entering these environments presents students with the opportunity to explore and learn about sexual relationships and their sexual identity. Cooper (2002) highlights that this provides opportunity to grow, however, it also presents the risk of having adverse or harmful sexual experiences. Associations have been identified with the consumption of alcohol and engaging in specific sexually risky behaviour (Cooper, 2002). Moreover, alcohol consumption has been shown to lead to risky partner choice and decreased discussion about safe sex (e.g. use of contraception and sexual history). Although there is evidence for the aforementioned risks, the evidence for associations between alcohol consumption and the use of contraception remains ambiguous (Cooper, 2002). This ambiguity is supported by findings from this review, with no direct association between alcohol consumption and SRH being identified. This is further supported by Blanchard et al (2018) who emphasise that there is currently little known about the associations between alcohol consumption and sexually risky behaviour. However, alcohol was consistently reported by the literature (37.5\% of papers reviewed) as an important consideration for tertiary institutions, despite the lack of information regarding the specific risks of alcohol consumption on SRH. Although this is an area that needs to be explored further, the lack of conclusive research suggests that the benefits of incorporating alcoholmitigating initiatives on tertiary campuses may have limited benefit to the overall sexual health and safety of students, staff members and the wider community. Despite this, it is believed that alcohol consumption and sexual behaviour are associated, even though the full extent of this association is not currently known. Therefore, it is unlikely to be detrimental, and may in fact be advantageous to incorporate alcohol and substance abuse interventions into SRH services on tertiary campuses. 


\section{Sexually transmitted infection screening and high-risk sub-populations}

University students are particularly vulnerable to STIs, with studies showing that university and college students are more likely to engage in sexually risky behaviour (Denison, Bromhead, Grainger, Dennison, \& Jutel, 2017). However, STIs are largely preventable and treatable despite the high rates seen in tertiary students and young adults. In addition to the high STI rates seen in tertiary students overall, there are large disparities between Indigenous and non-Indigenous students. These differentials between Indigenous and non-Indigenous students remain consistent across multiple countries, as identified within this review. Indigenous and Aboriginal populations were reported by $37.5 \%$ of the literature as being at highest risk of contracting STIs, having poor knowledge of SRH, having limited access to SRH services and being more socially excluded. This does not mean that non-Indigenous populations are not a priority. However, it does highlight the importance of gathering demographic information to identify students, staff and other community members who may be at greater risk of contracting an STI. Tertiary institutions have the opportunity to minimise the health burden of STIs within the community through the development and delivery of STI screening and SRH services on campus. Further, these services can play a vital role in gathering demographic information needed to identify high-risk groups and implement targeted health interventions to improve the overall health and wellbeing of students, Indigenous populations and other high-risk sub-populations. Other benefits of SRH and STI screening services include the opportunity to provide SRH education, identification of SRH issues within individuals and the wider population, the provision of effective contraception and the potential to gather information for progressing SRH research within tertiary environments. Outside of clinical services, promoting social inclusion across diverse populations is likely to improve access and uptake of services for Indigenous and other diverse groups of students and community members.

\section{Contraception}

It is often true that the most rudimentary forms of health interventions are the most effective, such as the benefits of mosquito nets in preventing the spread and contraction of malaria. This is also true when looking at SRH, with the male latex condom overwhelmingly demonstrated to be an effective means of contraception. The use of contraception is widely considered essential to limiting the risk of contracting an STI and being an effective method of preventing unwanted pregnancy. Therefore, proper contraception use can be considered a crucial aspect of SRH and should be an important part of promoting sexual health within tertiary environments. This is supported by Eastman-Mueller et al (2016, p190) who state, "consistent use of a male latex condom significantly reduces the risk of STIs, including human immunodeficiency virus (HIV) and unintended pregnancies". The importance of condom use was further emphasised by this review, with the majority of the literature mentioning condoms as an important factor for promoting SRH within tertiary environments. Moreover, condoms were the most consistently reported form of contraception cited within the literature. Given the wide-ranging benefits of condoms and contraception more broadly, it is recommended that tertiary institutions ensure sufficient access to condoms and other forms of contraception on campus, as increased availability, accessibility and acceptance have been shown to increase the safe use of contraception during sexual intercourse (Eastman-Mueller et al, 2016; Eisenberg et al, 2013). Further, this review identified wide-reaching considerations when looking at the promotion of contraception use, which include gender expectations, STI education, contraception type and demographic influences upon the use of contraception. In addition to ensuring adequate accessibility, it is crucial that tertiary institutions deliver appropriate education about safe sex practices and the importance of contraception for protecting against STIs and unwanted pregnancy.

\section{Education programs and peer involvement}

Health education is an important aspect of health promotion, as it spreads knowledge throughout 
the wider community that helps to facilitate greater autonomy in self-care and health management for individuals. SRH education was discussed by $81.25 \%(\mathrm{n}=13)$ of the literature. This is as frequently mentioned as total contraception use throughout the literature. It is therefore clear that SRH education is a crucial aspect of providing SRH services and resources on tertiary campuses. Further, targeted SRH education is critical, as it has been shown that there are conflicting perceptions and a general misunderstanding of many aspects of SRH amongst college and university students. Moreover, ensuring education and intervention is targeted at all genders and key demographics has been demonstrated as fundamental to the success and effectiveness SRH services and resources delivered within tertiary environments (Martin et al, 2011). It must be emphasised that merely having services and resources is not enough on its own. Individuals are unlikely to access health services if they do not understand the risks or the potential consequences of their sexual behaviour, in addition to the health interventions that are available to them. Tertiary institutions should not only provide the tools for positive SRH, but also provide education about how to use those tools effectively. Education targeted at STIs, contraception use and available health services can be promoted on campus to individuals that are at an age where sexual exploration may expose them to serious SRH risks. Tertiary institutions are in a unique position to targets this younger demographic and provide them with the knowledge to effectively manage their $\mathrm{SRH}$, which may have potential life-long benefits for their overall health and wellbeing. It is also true that peer involvement should be utilised in the delivery of SRH services and SRH education programs, with peer involvement mentioned by just under half $(43.75 \%)$ of the literature as beneficial to the success of SRH services and initiatives provided on tertiary campuses. Peer involvement in SRH promotion provides a number of opportunities for tertiary institutions, which includes greater uptake of services by students, direct input from key demographics targeted by SRH initiatives and the opportunity to facilitate trans-disciplinary collaboration, which is identified by the Okanagan Charter as a significant factor in creating healthy university and college environments. Peer involvement in SRH promotion can help tertiary institutions meet their obligations in facilitating and supporting healthy campus environments, whilst delivering applied education through the provision of SRH services and programs.

\section{Limitations}

While this review presented a comprehensive synthesis of published research a potential limitation is that literature like unpublished masters and doctoral theses were excluded from the search. Even so Vickers and Smith (2000) noted that after a review of the Cochrane Library, only one of 878 systematic reviews included data from theses that could have fundamentally altered the conclusions of those reviews. Nevertheless, Vickers and Smith (2000) noted that the benefits of including dissertations in systematic reviews are minimal as they rarely influence the conclusions, whilst retrieving and analysing unpublished dissertations involves considerable time and effort.

This study is further limited by the disproportionate number of papers focused on research conducted in the USA. This lack of diversity of the literature has a few implications. First, the views presented are limited to those of a particular sociocultural, political and economic setting in which multiculturalism has been a long-standing discussion resulting from America's extensive history of migration and the aftermath of that history for many ethnic groups. Second, this means that the experiences and views of mental health care workers in other contexts, which have very different, (and some with much shorter) histories of migration, are not heard, or are swamped by those from the USA. Whilst this may simply indicate that such conversations are in their infancy or adolescence (e.g., like in Australia) the lack of perspectives from other geographic regions limits insights for both the therapeutic alliance and cultural competency in relation to minority populations in those countries (e.g., Indigenous Australians). Lastly, it is important to note that although this review identifies key considerations for tertiary institutions in the planning, 
development and implementation of SRH promotion, further research is needed to provide a comprehensive framework for SRH provision on tertiary campuses.

\section{Conclusion}

Tertiary institutions have a unique opportunity to promote SRH throughout the wider community and target key demographics that are at high risk of having poor SRH. SRH can be promoted to students, employees and members of the wider community through the delivery of services, education programs, development of SRH research and the promotion of SRH more broadly. In addition to the recommendations of the Okanagan Charter, this review identifies recommendations for tertiary institutions to effectively promote SRH on campus. Creating supportive campus environments was identified within the literature as a fundamental concern for the promotion of SRH. Moreover, it is important for tertiary institutions to recognise barriers to the success and uptake of SRH services on campus, which may be unique to each individual tertiary institution. Religious and ideological barriers were the most frequently reported within the literature, but other barriers may include a lack of socially inclusive campus environments, absence of nondiscrimination policies (both direct and indirect) and limited access to services targeted at diverse demographics. 'Creating supportive campus environments' ensures that all individuals and stakeholders feel safe, supported and have equal access to on-campus services. This review helps to reinforce the understanding that university and college environments play an important public health role throughout the wider community. They provide education, employment, scientific research and public services that can promote the health and wellbeing of students, employees and the wider community. Further, tertiary campuses provide social environments, access to social networks and the resources required to achieve upward social mobility. This unique opportunity to promote health in its broader context is highlighted by the Okanagan Charter, however, given the comprehensive nature of the charter, it does not directly address SRH. In order to ensure an effective guide to SRH promotion within tertiary environments, this review recommends the key considerations mentioned above be adopted when developing on-campus SRH programs and initiatives. In summary, these recommendations are: to utilise pilot programs in the development and ongoing evaluation of SRH initiatives; include peers in the ongoing delivery of SRH services; identify key demographics and high-risk sub-populations relevant to the institution and surrounding geographical area; provide targeted SRH education programs; and ensure accessibility to STI screening and contraception on campus. 


\section{References}

Ahmed, S., Shommu, N.S., Rumana, N., Barron, G.R., Wicklum, S., \& Turin, T.C. (2016). Barriers to access of primary healthcare by immigrant populations in Canada: A literature review. Journal of Immigrant and Minority Health, 18(6), 1522-1540. doi:10.1007/s10903-015-0276z

American College Health Association (ACHA). (2015). Okanagan Charter: An international charter for health promoting universities and colleges. Retrieved from:

https://internationalhealthycampuses2015.sites.olt.ubc.ca/files/2016/01/Okanagan-CharterJanuary13v2.pdf

Arksey, H., \& O’Malley, L. (2005). Scoping studies: Towards a methodological framework. International Journal of Research Methodology, 8(1), 19-32. doi:10.1080/1364557032000119616

Australian Bureau of Statistics (ABS). Sexually Transmissible Infections. Retrieved from: http://www.abs.gov.au/AUSSTATS/abs@.nsf/Lookup/4102.0Main+Features10Jun+2012\#Bacterial

Australian Institute of Health and Welfare (AIHW). 2017. Incidence of sexually transmissible infections and bloodborne viruses. Retrieved from: https:/www.aihw.gov.au/reports/australias-health/australias-health2018/contents/indicators-of-australias-health/sexually-transmissible-infections-bloodborne-virus

Baker, M., Ortega-Benito, J., Garret, N., Bromhead, C., Leslie, K., MacDonald, J., McNicholas, A. (2005). Prevalence and risk factors for chlamydia trachomatis infection in female New Zealand university students. The New Zealand Medical Journal, 118(1220), 1-12. Retrieved from: http://www.nzma.org.nz/joumal/118-1220/1607/ *

Blanchard, B.B., Stevens, A.K., Acosta, I.S., Talley, A.E., Brown, J.L. \& Littlefield, A.K. (2018). The influence of motives on alcohol and sex-related behaviours among female college students. Drug and Alcohol Dependence, 185, 120-126. https://doi.org/10.1016/j.drugalcdep.2017.11.039

Butler, S.M., Hartzell, R.M., Przybyla, S., \& Bickers Bock, L.B. (2006). Moving beyond peer education: Using peer advocates to increase condom availability on colleges campuses. Perspectives in Peer Programs, 20(2), 40-45. Retrieved from:

http://go.galegroup.com.ezproxy.uws.edu.au/ps/i.do?id=GALE\%7CA266140265\&v=2.1\&u=uwsydn ey\&it $=\mathrm{r} \& \mathrm{p}=\mathrm{AONE} \& \mathrm{sw}=\mathrm{w} \# *$

Children By Choice. (2017). Unplanned pregnancy in Australia. Retrieved from https://www.childrenbychoice.org.au/factsandfigures/unplannedpregnancy

Cooper, L.M. (2002). Alcohol use and risky sexual behavior among college students and youth: Evaluating the evidence. Journal of Studies on Alcohol, 101-117. Retrieved from:

http://link.galegroup.com.ezproxy.uws.edu.au/apps/doc/A87781228/AONE?u=uwsydney\&sid=AON E\&xid=f55fee $2 \mathrm{~d}$

Cronin, J. (2012). Britain in the world: Implications for the study of British politics. British Politics, 7(1), 55-68. doi:10.1057/bp.2011.36

Currie, M.J, Schmidt, M., Davis, B.K., Baynes, A.M., O’Keefe, E.J., Bavinton, T.P., McNiven, M., Martin, S.J., \& Bowden, F.J. (2010). 'Show me the money': Financial incentives increase chlamydia screening rates among tertiary students: A pilot study. Sexual Health, 7, 60-65. doi:10.1071/SH08091 *

Denison, H.J., Bromhead, C., Grainger, R., Dennison, E.M., \& Jutel, A. (2017). Barriers to sexually transmitted infection testing in New Zealand: A qualitative study. Australian and New Zealand Journal of Public Health, 41(4), 432-437. doi:10.1111/1753-6405.12680

Eastman-Mueller, H.P., Gomez-Scott, J.R., Jung, A., Oswalt, S.B., \& Hagglund, K. (2016). Implementation and evaluation of a condom availability program on a college campus: Lessons from the field. American Journal of Sexuality Education, 11(3), 189-204. doi:10.1080/15546128.2016.1198735 *

Eisenberg, M.E., Hannan, P.J., Lust, K.A., Lechner, K.E., Garcia, C., \& Frerich, E.A. (2013). Health resources at Minnesota colleges: Associations with students' sexual behaviours. Perspectives on Sexual and Reproductive Health, 45(3), 132-138. doi:10.1363/4513213*

Family Planning Victoria. (2018). Teenage Pregnancy. Retrieved from: https://www.fpv.org.au/foryou/pregnancy/teenage-pregnancy

Fields, C.D. (2002). Sexual responsibility on campus: Institutions take a closer look at their role in today's sexually tolerant environment. Black Issues in Higher Education, 18(25). Retrieved from: 
http://web.b.ebscohost.com.ezproxy.uws.edu.au/ehost/detail/detail?vid=0\&sid=aeb2de4d-1b7c-43c7-926e1c57a4b5eab1\%40sessionmgr104\&bdata=JnNpdGU9ZWhvc3QtbG12ZSZzY29wZT1zaXRl\#AN=6069912\&d $\mathrm{b}=\mathrm{ehh} *$

Gibb, M. (2003). Intrusive sex questions anger HKU students: University health service also seeks data on smoking, alcohol consumption and family medical history but ignores Sars. South China Morning Post. Retrieved from: https://www.scmp.com/article/428543/intrusive-sex-questions-anger-hku-students

Gilchrist, H., Smith, K., Magee, C.A., \& Jones, S. (2012). A hangover and a one-night stand: Alcohol and risky sexual behaviour among female students at an Australian University. Youth Studies Australia, 31(2), 35-44. Retrieved from: http://web.b.ebscohost.com.ezproxy.uws.edu.au/ehost/detail/detail?vid=0\&sid=37c52e9c-9c37-429ab420-

d6a511f61534\%40sessionmgr103\&bdata=JnNpdGU9ZWhvc3QtbG12ZSZzY29wZT1zaXRl\#AN=77572565\& $\mathrm{db}=\mathrm{sih}$

Hofstede, G. (2009). Dimensionalising cultures: The Hofstede Model in context. Online Readings in Psychology and Culture. Retrieved from: https://pdfs.semanticscholar.org/db64/f58d8b341fabda575502f071843dd3895bd6.pdf

Hofstede, G. (n.d.). The 6-D model of national culture. Retrieved from: https://geerthofstede.com/culture-geerthofstede-gert-jan-hofstede/6d-model-of-national-culture/

Holt, M., \& Powell, S. (2016). Health Universities: A guiding framework for universities to examine the distinctive health needs of its own student population. Perspectives in Public Health, 20(11), 1-6. doi:10.1177/1757913916659095*

Jacobsen, V., Mays, N., Crawford, R., Annesley, B., Christoffel, P., Johnston, G., \& Durbin, S. (2002). Investing in well-being: an analytical framework. New Zealand Treasury Working Paper 02/23. New Zealand Treasury: Wellington. Retrieved from: https://treasury.govt.nz/sites/default/files/2007-09/twp02-23.pdf

Kistin, C. \& Silverstein, M. (2015). A critical but misused component of interventional research. The Journal of the American Medical Association, 314(15), 1561-1562. doi:10.1001/jama.2015.10962

Lee, P.A., \& Lee, D.L. (1989). Condom machines on college campuses. Journal of Adolescent Health Care, 10(6), 582584. doi:0197-0070/89/3.50*

Leon, A.C., Davis, L.L., \& Kraemer, H.C. (2011). The role and interpretation of pilot studies in clinical research. Journal of Psychiatric Research, 45, 626-629. doi:10.1016/j.jpsychires.2010.10.008

Martin, E., Senior, N., Abdullah, A., Brown, J., Collings, S., Racktoo, S., Walpole, S., \& Zeito, M. (2011). Perceptions of HPV vaccine amongst UK university students. Health Education, 111(6), 498513.doi:10.1108/09654281111180481*

McCarthy, S.K. (2002). Availability of emergency contraceptive pills at university and college Student Health Centers. Journal of American College Health, 51(1), 15-22. doi:10.1080/07448480209596323*

McClean, H., Sutherland, J., Searle. S., \& Howarath, P. (2000). An exploratory study of information-giving used to promote chlamydial test-seeking by students at a college family planning clinic. The British Journal of Family Planning, 26(4), 209-212. doi:10.1783/147118900101194814*

McKeller Miller, L., \& Sawyer, R.G. (2006). Emergency contraceptive pills: A 10-year follow-up survey of use and experiences at college health centers in the Mid-Atlantic United States. Journal of American College Health, 54(5), 249-256. doi:10.3200/JACH.54.5.249-256*

MacPhail, C., Dune, T., Dillon, G., Rahman, S., Khanam, R., Jenkins, L., Britton, M., Green, B., Edwards, C. \& Stevenson, A. (2017). Knowledge and attitudes to sexual health and STI testing for students at an Australian regional university: a cross-sectional study. Journal of the Australian and New Zealand Student Services Association, 49(1), 36-48. Retrieved from: https://ro.uow.edu.au/sspapers/2933/

OECD Data (2017). Population with tertiary education. Retrieved from: https://data.oecd.org/eduatt/population-withtertiary-education.htm\#indicator-chart

Singh, S., Darroch, J.E., Ashford, L.S., \& Vlassoff, M. (2009). Adding it up: The costs and benefits of investing in family planning and maternal and newborn health. Guttmacher Institute and UN Population Fund: New York. Retrieved from: https:/www.guttmacher.org/sites/default/files/report_pdf/AddingItUp2009.pdf

Skinner, R.S., \& Hickey, M. (2003) Current priorities for adolescent sexual and reproductive health in Australia. Medical Journal of Australia, 179 (3), 158-161. Retrieved from:

https://www.mja.com.au/journal/2003/179/3/current-priorities-adolescent-sexual-and-reproductivehealth-australia 
Temple-Smith, M., \& Gifford, S.M. (Eds) (2005). Sexual health: An Australian perspective. Melbourne, Australia: IP Communications.

Twohey, M. (2006). University sex program arouses excitement, dismay. Milwaukee Journal Sentinel. Retrieved from: https://search-proquest-

com.ezproxy.uws.edu.au/docview/456686393/44997099452349FEPQ/1 ?accountid=36155*

Vickers, A., \& Smith, C. (2000) Incorporating data from dissertations in systematic reviews. International Journal of Technology Assessment in Health Care, 16(2), 711-3. Retrieved from: https:/www-cambridgeorg.ezproxy.uws.edu.au/core/services/aop-cambridgecore/content/view/212685BC34DC44B66934B7612F0BD128/S0266462300101278a.pdf/incorporating_data_f rom_dissertations_in_systematic_reviews.pdf

Vlassoff, M., Singh, S., Darroch, J., Carbone, E., \& Bernstein, S, (2004). Assessing costs and benefits of sexual and reproductive health interventions. Occasional Report No. 11. The Alan Guttmacher Institute: New York \& Washington. Retrieved from: http:/www.guttmacher.org/pubs/2004/12/20/or11.pdf

Wilson, K., Steenbeek, A., Asbridge, M., Cragg, A., \& Langille, D.B. (2015). Sexual health among female Aboriginal university students in the Maritime Provinces of Canada: Risk behaviours and health services use. Sexual Health, 13,35-42. http://dx.doi.org/10.1071/SH151*

Women's Health West. (2011). Social determinants of sexual and reproductive health: 2011 report. Retrieved from: https://whwest.org.au/wp-content/uploads/2012/06/SocDet_Web.pdf

World Health Organisation. (2008). Integrating poverty and gender into health programmes: A sourcebook for health professionals (Sexual and reproductive health). Retrieved from:

http://www.wpro.who.int/publications/docs/22_October_2008_Module_on_SRH_web.pdf?ua=1

World Health Organisation (2006). Defining sexual health. Retrieved from:

http://www.who.int/reproductivehealth/topics/sexual_health/sh_definitions/en/

Yves, H., Bernard, J. de Man, A.F. \& Farrar, D. (1989). Factors related to the use of condoms among French-Canadian university students. The Journal of Social Psychology, 129(5), 707-709. Retrieved from: https://searchproquestcom.ezproxy.uws.edu.au/docview/57537263?accountid=36155\&rfr_id=info\%3Axri\%2Fsid\%3Aprimo

*Articles scoped/used in review

The authors may be contacted via:

j.delacy@hotmail.com

Please cite this paper as:

DeLacy, J., Saheb, R., Rutherford, E., Garcia, R.G., \& Dune, T. (2019) Sexual and reproductive health services and promotion in tertiary institutions: A systematic content review. Journal of the Australian and New Zealand Student Services Association, 27(1), 45-61. doi.org.10.30688/janzssa.2019.05 